$\triangle$ WEW TYPE OF MOTOR CAR. An entirely novel form of
voiturette has recently been patented and put to practical test in England by M. Maberly-Smith, of Penshurst, Kent, the construction of which involves one or two new principles.

The illustration gives a general idea of the vehicle, and demon. strates that although the car is tandem in form, the occupants, who have considerable seating accommodation, are so arranged that the modation, are so arranged that the the rearmost seat, has a clear view of the road as well as the advantage of sociability with the foremost occupants. The position of the steering rod, starting handle, belt controller, and other small levers directly in front of the driver is also to be noted.

The main feature in the construction of this vehicle is the central trough or hollow keel, which contains practically the whole mechanism; in the latest pattern even the steering rods are inclosed within this keel, while the belt, pulleys, and chains are kept dry and free from dust, so that they work under ideal condition The engine alone with its carbureter is not in closed, but is mounted on the extreme end of the keel and has the full advantage of the cooling influence of the atmosphere.

The keel is practically the frame of the car, and to this is attached the bent-wood construction which forms the backs and footboards of the seats.

The wheels, as will be seen, are placed in diamond form, though the two steering wheels, having their position one at each end of the keel, are not actually in the same line. The reason for this is perhaps not at first obvious. In reality, however, the compactness of the design entirely depends upon this vital point, as by this means the transmission is rendered central, and the steering wheels coming immediately below the weight they have to support are permitted ample room for locking; in fact, the car can turn within a radius of 10 feet, partly owing no doubt to the duplicate method of steering, which has among other things entirely abolished the tendency to side slip so commonly found in motor vehicles. Some of the cars were recently exhibited at the Crystal Palace National Show, fitted with a $23 / 4$ horse power De Dion water-cooling engine, which has been found to give ample power even with the two speeds with which the cars are now furnished. Gasoline is not the only power suited to this type of car, however, its extreme lightness of four hundred weight, including tanks, engine, and accessories, rendering it suitable for electric propulsion, which is now in contemplation. It is thought there will be sufficient room to carry the batteries within the cent:al trough before mentioned.

\section{A PNEUMATIC FIRE ESCAPE AND TOWER.}

BY wiLlaM S. CRANDALL.
All things considered, the city of Pittsburg has in many respects the most up-to-date fire department in the United States. Its latest acquisition is a pneumatic telescopic aerial truck. This is the first piece of apparatus of its kind in America. It has been used for the last five years in the leading European cities and is the invention of a German scientist.

It was given a successful test the other day in Pittsburg, when it lifted from one to three men, each with a section of hose, to any particular window desired in a five-story building. The apparatus is worked by compressed air. This is a great advantage over the old style, as much valuable time is saved. The ordinary aerial truck cannot be utilized to as good advantage as this new invention. A tank of 300 pounds pressure supplies the force to shoot a heavy ladder into the air. Another smaller tank of 100 pounds pressure makes it possible to use it on buildings on either side of the street, so that although the ladder is 85 feet high, and would appear cumbersome and unwieldy to the uninitiated, yet it can be managed with the greatest ease and accuracy. The

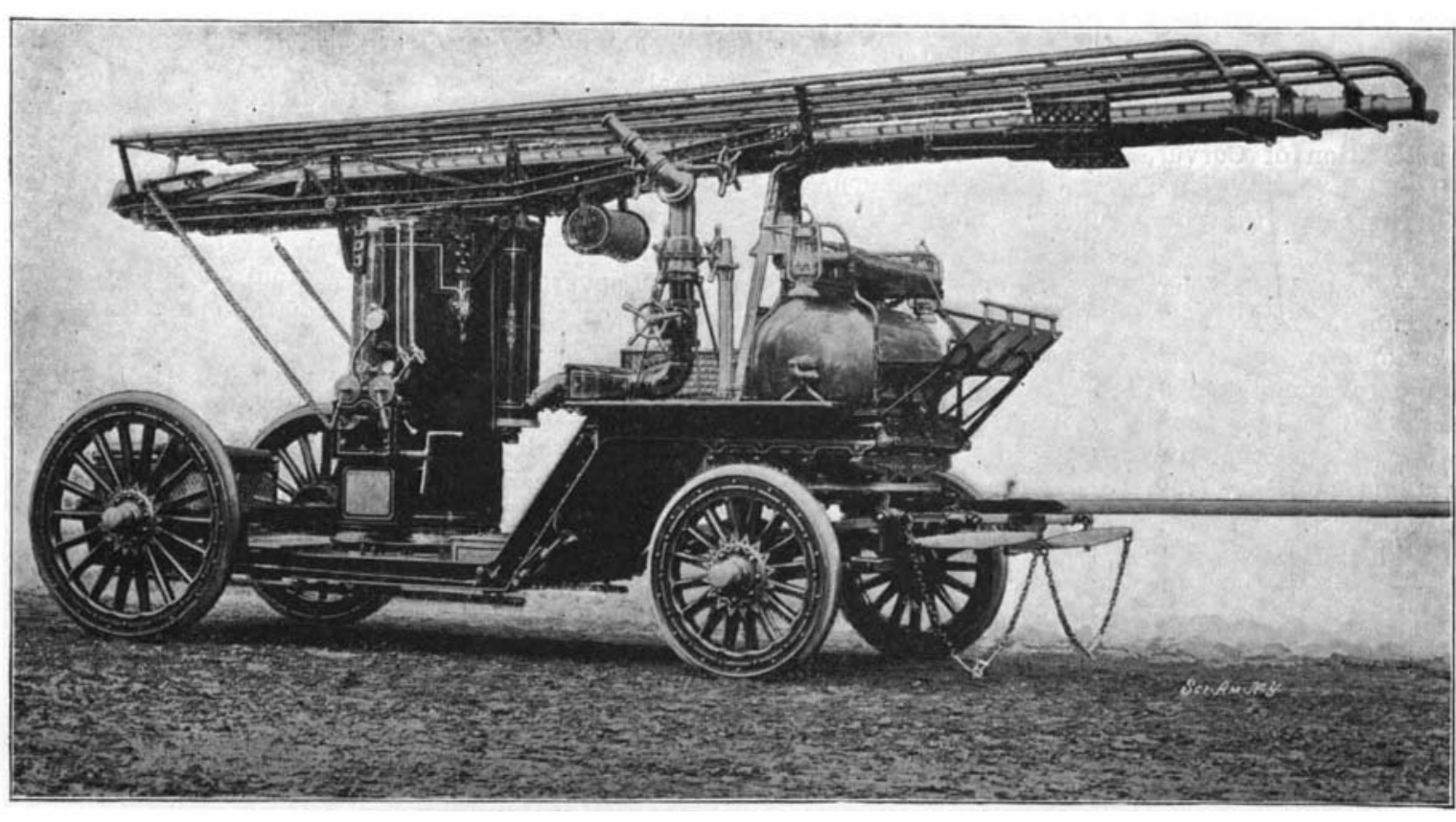

PNEOMATIC, TELESCOPIC, ELECTRICALLY-INSULATED, AERIAL HOOR-AND-LADDER TROCR.
When it is desired to enter a certain window in a burning building, whether it be in the first or fifth story, a fireman is securely fastened to the top of the telescopic tube, when the first section is extended into the air, two men being required to operate the machine, one freeing the big tank from air, while the other applies the air to the tubes. Then the second, third and fourth sections are raised in the same manner, the time consumed in the operation being much less than it takes to tell about it. While the piece of apparatus is exceedingly valuable in fighting fire in tall buildings, yet its principal use will be that of a life saver. To step out of a fifth-story window on to the top of an aerial ladder is a ticklish piece of busi. ness. To descend such a ladder is still more difficult and trying to the nerves of those who have not had the training of a fireman. To a woman the ascent or descent of a ladder, with her unmanageable skirts, the situation is still more difficult, and especially so when truck on which the ladder is mounted weighs 10,000 pounds, which does away with all danger of tilting. The wheels are fitted with rubber tires and roller

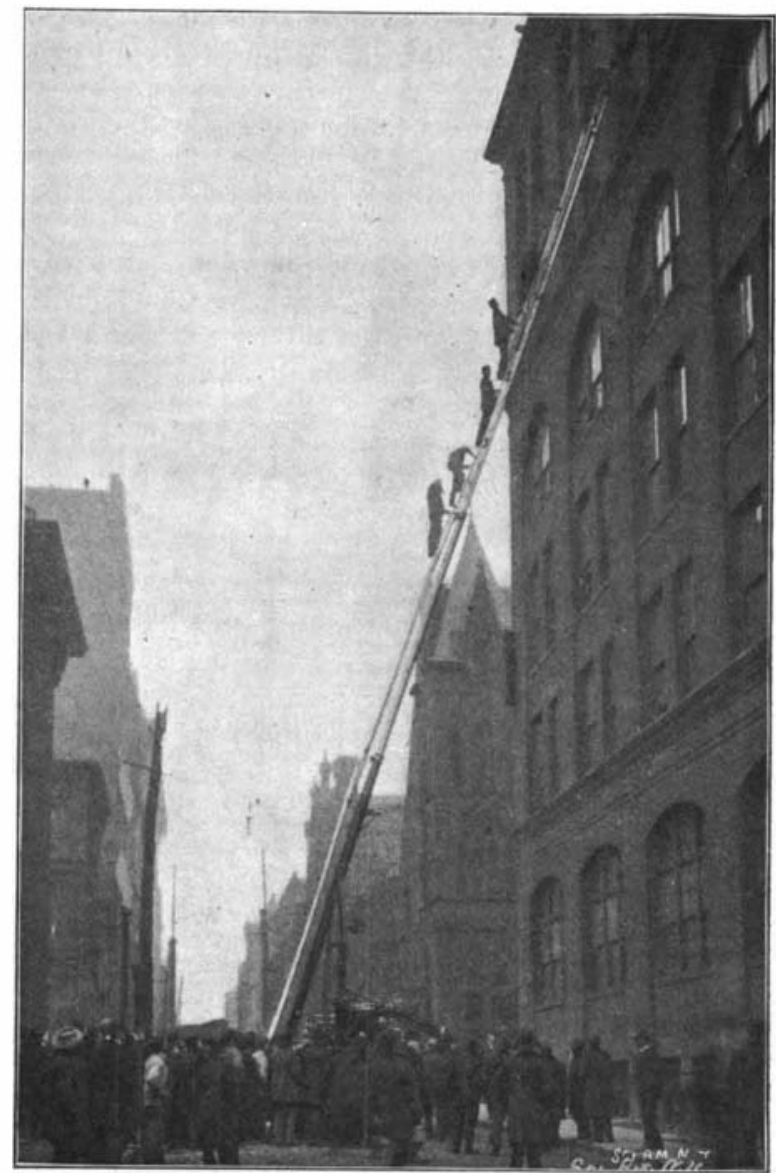

THE PNEUMATIC AERIAL TRUCR IN OPERATION.

bearing axles, and the truck can be easily drawn by two horses. There is a chemical fire engine and water tower equipment in combination, together with water tower equipment in combination, together with danger threatens and one is surrounded by flame and smoke. The use of this pneumatic ladder does away with all of these nerve-racking ordeals, making the descent from the window of a burning building a comparatively simple experience. At the top of the ladder is a little platform, and a fireman is always at hand ready to assist the person in danger from the window to the platform. Then one section after another of the tube is telescoped, and the person brought safely to the ground without any of the harrowing experiences incident to the descent of a long ladder.

No doubt the introduction of this expensive pneumatic ladder into the Pittsburg department will be rapidly followed by other large cities of the United States. In those cities outside of New York, Chicago and Philadelphia this mode of rescuing people from burning buildings would be possible in almost every instance; but in the cities mentioned, where the business blocks and apartment houses range from eight to sixteen stories high, it would be practically useless. In such cases the scaling ladder, as employed by the New York Life-Saving Corps, would be the only available substitute. But in the smaller cities, where nearly all the buildings are five stories in height or less, the new apparatus can be used to the greatest advantage.

There is really greater need for life-saving apparatus in this country than in Great Britain or the continent, for the reason that the building regulations in many American cities are either defective or loosely enforced as compared with those on the other side of the Atlantic. Here, in some cities the most flagrant abuses of building laws are tolerated, and little attempt is made to regulate the little points of detail, such as the use of matches, location of gas jets, proper installation of electric wires, proper care of chimneys, and the like. Most of our large cities have a more or less complete set of rules regulating these matters, but politics enter into the administration of a city's affairs so largely that they frequently nullify the efficiency of such rules. In London if a chimney burns out a fine is imposed upon the property owner, whether it happens to do any damage to surrounding buildings or not. The law is enforced for the purpose of making people careful to keep their chimneys clean, in order to avoid the possible conflagration.

Owing to the lax methods for fire prevention employed in this country, the annual loss by fire is far greater than that of the Old World. While we have great reason to be proud of the efficient fire service in American cities as a whole, yet it needs to be the more per fect because of the greater number of fires and the greater menace to public property.

Emperor Wilhelm has presented his yachts "Meteor" and "Comet" to the German navy. The "Meteor" is the use or the use of the naval officers at Kiel and will be renamed the "Orion," while the "Comet" is for the use of the officers at Wilhelmshaven. 